\title{
Degradation of Acetonitrile Residues Using Oxidation Processes
}

\author{
Regina C. da C. M. Micaroni, Maria Izabel M. S. Bueno* and Wilson de F. Jardim \\ Instituto de Química, Universidade Estadual de Campinas, CP 6154, 13084-971 Campinas - SP, Brazil
}

\begin{abstract}
Neste trabalho são relatados vários processos de oxidação para a degradação de acetonitrila. Foram investigadas alternativas como fotólise, degradação com peróxido de hidrogênio, processos Fenton e foto-Fenton. A fotólise, o processo mais simples e de menor custo dentre os avaliados, promoveu $100 \%$ de degradação de soluções aquosas de acetonitrila a 20\%, após 30 horas de irradiação. Este método apresenta, portanto várias vantagens dentre as opções a serem usadas em processos de decomposição de resíduos tóxicos de acetonitrila, os quais tendem a se acumular em laboratórios que utilizam equipamentos de Cromatografia Líquida de Alta Eficiência com Fase Reversa.
\end{abstract}

Several oxidation processes were investigated to degrade residues of acetonitrile. Alternatives such as photolysis, degradation with hydrogen peroxide, Fenton and photo-Fenton processes were investigated. Among the options studied, photolysis proved to be the best choice. Photolysis promoted $100 \%$ degradation of $20 \%$ aqueous acetonitrile solutions in 30 hours. This method proved to be a cheap alternative to decompose toxic residues of acetonitrile, which tend to be accumulated in laboratories that use RP-HPLC equipments.

Keywords: acetonitrile, oxidation process, degradation

\section{Introduction}

In the last few years, Universities and Research Institutions in Brazil have started looking for alternatives to deal properly with their growing amounts of chemical residues. Within this context, many institutions have developed Waste Management Programs aiming to reduce, reuse and recycle their chemical residues. ${ }^{1-3}$ The "Waste Management Program of the Chemistry Institute of Universidade Estadual de Campinas (UNICAMP)" includes the monitoring of the residue generated, the development of alternatives to reduce its amount and potential hazardous toxicity, as well as the evaluation of alternatives to treat residues which present incineration restrictions. ${ }^{4}$ It is worthwhile mentioning that the organic residues generated by Chemistry Institute of UNICAMP are decomposed by incineration and the treatment of aqueous solutions containing heavy metal is carried out by precipitation of the heavy metal in loco, at their generating units. Therefore, the residues that require more attention are aqueous solutions containing organic compounds, which deserve a study of possible degradation alternatives.

* e-mail: bell@iqm.unicamp.br
Acetonitrile is used in different processes in the chemical industry as a starting material for the synthesis of many chemicals, pharmaceuticals and pesticides, and also in the manufacturing of photographic films. Another common use of this substance is in research laboratories, mainly diluted in water, as mobile phase in Reversed Phase High Performance Liquid Chromatography (RP-HPLC). ${ }^{5}$ The literature presents several indications of health hazards in expositions to it. ${ }^{5}$ Aqueous residues of acetonitrile are critical at Chemistry Institute of UNICAMP and the Safety Committee has been carrying out their treatments through alkaline hydrolyses. These are also critical in all institutions that use RP-HPLC (Reversed Phase High Performance Liquid Chromatography) equipments, once mixtures of acetonitrile and water are commonly used as mobile phases in these systems. As a result, residues containing acetonitrile in water are troublesome not only for their toxicity, but also due the high frequency and quantity they are generated.

Aiming to reduce the use of acetonitrile in RP-HPLC, Ichinoki et al. ${ }^{6}$ studied the use of distinct aliphatic alcohols as mobile phases for separations of polyaromatic hydrocarbons using $\mathrm{C} 18$ columns. In this specific case, these researchers found that the substitution could be done with excellent results. Ribeiro et al. ${ }^{7}$ also reported the use 
of ethanol instead of acetonitrile in RP-HPLC with very good results. Gilomen et al..$^{8}$ suggested the minimization of the residue containing acetonitrile by reducing the internal diameter of the chromatographic column, from 4.6 to $2 \mathrm{~mm}$. Nevertheless, the literature shows still an accentuated use of acetonitrile by HPLC users, since only from January to September 2003, more than 290 scientific papers indicate HPLC procedures mentioning the use of this solvent. ${ }^{9}$

Recycling of mixtures of acetonitrile/water used in RPHPLC through distillation is not advisable, once these substances form an azeotropic mixture containing $84 \%$ (volume) of acetonitrile. Although this mixture can be obtained in a purity degree that allows its recycle for RPHPLC purposes, the cost and resistance for reusing/ recycling have not allowed such a practice. However, commercial HPLC equipments containing a closed looprecycling device are available with ${ }^{10}$ or without ${ }^{11}$ solvent purification by adsorption of impurities onto activated carbon. This device is not adequate at all for gradient applications in HPLC.

The alternatives for final disposition of aqueous residue containing acetonitrile are combustion or biological/chemical decomposition. The combustion process requires a very careful consideration since the formation of undesirable toxic by-products through incomplete incineration is possible to occur. Furthermore, this residue is rich in water, which increases the transportation and incineration costs. Nieder ${ }^{12}$ and coworkers developed a biological degradation procedure to convert acetonitrile to ammonium acetate. These researchers used many bacteria species, which were active only at an acetonitrile concentration below $15 \%, \mathrm{pH}$ from 3 to 11 and temperatures below $50^{\circ} \mathrm{C}$. In 1995, Gilomen et $a l .^{8}$ described a methodology using alkaline hydrolysis to decompose aqueous acetonitrile residues. In this process, acetonitrile concentrations should be below $10 \%$ and a molar ratio of $2.5 \mathrm{~mol}$ of sodium hydroxide to $1.0 \mathrm{~mol}$ of acetonitrile was used.

The literature shows few examples of Advanced Oxidation Processes (AOP) for the degradation of acetonitrile residues and the processes studied were restricted to heterogeneous photocatalyses. In 1996 Lichtin and Avudaithai ${ }^{13}$ described a comparative study to degrade acetonitrile in vapor phase and in aqueous solutions using AOP. These authors used heterogeneous photocatalyses with $\mathrm{TiO}_{2}$ in stirred batch reactors with a continuous oxygen supply. UV irradiation was performed using a fluorescent lamp (360 nm, 6W). $\mathrm{NO}_{2}, \mathrm{HNO}_{3}, \mathrm{CO}_{2}$ and $\mathrm{C}_{2} \mathrm{~N}_{2}$ were identified as products of the degradation. In 1999, Zhuang and co-workers ${ }^{14}$ reported a study of the photo-oxidation mechanism of acetonitrile chemisorbed in $\mathrm{TiO}_{2}$ using infrared spectroscopy. Under UV irradiation $(350 \pm 50 \mathrm{~nm}$; $\mathrm{h} v=3.10-4.13 \mathrm{eV}$ ), acetonitrile was oxidized in the presence of $\mathrm{O}_{2}$ to form $\mathrm{H}_{2} \mathrm{O}, \mathrm{CO}_{2}$, surface carbonated products and an intermediate partially oxidized isocyanate species, $\mathrm{NCO}$, which was identified by various isotopic experiments. Nevertheless, the results presented by these authors were not enough to elucidate the complete photooxidation mechanism for the degradation of acetonitrile in $\mathrm{TiO}_{2}$ surfaces.

According to what was previously mentioned, the study of the degradation of aqueous residues containing acetonitrile through advanced oxidation processes proved to be of utmost importance. This study shows results of some oxidation processes to decompose acetonitrile, however with no evaluation of the products and/or intermediates formed during the degradation, that will be subject of future investigations.

\section{Experimental}

\section{Equipments}

The rate of acetonitrile decomposition was measured through dissolved organic carbon (DOC) using a Shimadzu TOC 5000 Total Organic Carbon Analyzer.

The light intensity at $365 \mathrm{~nm}$ was determined using a Cole-Parmer Radiometer series 9811.

The photochemical reactor was assembled using a steal reactor from Trojan with diameter of $6 \mathrm{~cm}$, length of $94 \mathrm{~cm}$ and a net volume of $2.25 \mathrm{~L}$. The light source was a mercury vapor lamp of $65 \mathrm{~W}$. The reactor was connected to a collecting plastic vessel of $10 \mathrm{~L}$ and to a pump (WEG 1HP) for the liquid samples circulation.

In the photolysis system, the light source is a Philips Powertone lamp (250W/220V). The reactor was assembled using a $3 \mathrm{~L}$ becker and a magnetic stirrer.

\section{Procedures}

Acetonitrile residue was collected at a Research Laboratory from the Chemistry Institute of UNICAMP. This residue was produced after RP-HPLC analyses of agrochemical products in organic extracts of human urine. A 40:60 mixture of acetonitrile (PA, Vetec) and water (Milli-Q) was used as mobile phase.

Acetonitrile degradation essays using solar light were carried out using $500 \mathrm{~mL}$ beckers containing $100 \mathrm{~mL}$ of acetonitrile residue and $230 \mathrm{~mL}$ of $50 \%$ hydrogen peroxide solution (Degussa). ${ }^{15}$ Hydrogen peroxide was added gradually in the following way: $50 \mathrm{~mL}$ in the beginning, 
$50 \mathrm{~mL}$ after each one hour for $2 \mathrm{~h}$ and, finally, $80 \mathrm{~mL}$ after $3 \mathrm{~h}$. Control tests were carried out in the darkness or using deionized water instead of hydrogen peroxide. The solutions were stirred manually at each $15 \mathrm{~min}$. Samples were collected and analyzed at each one hour of experiment.

For the photo-Fenton ${ }^{15}$ or ferrioxalate ${ }^{16}$ processes, $\mathrm{pH}$ was adjusted in 2-3, using sulfuric acid (PA ACS, Nuclear) before adding other reagents. In case of photo-Fenton, 0.30 $\mathrm{g}$ of $\mathrm{FeNH}_{4}\left(\mathrm{SO}_{4}\right)_{2} \cdot 12 \mathrm{H}_{2} \mathrm{O}$ (PA, Carlo Erba) was used for each $100 \mathrm{~mL}$ of $20 \%$ acetonitrile residue. In the ferrioxalate degradation of $100 \mathrm{~mL}$ of $20 \%$ acetonitrile residue, it was added $0.20 \mathrm{~g}$ of $\mathrm{K}_{3}\left[\mathrm{Fe}\left(\mathrm{C}_{2} \mathrm{O}_{4}\right)_{3}\right]$, (PA, Carlo Erba), prepared according to Nogueira et al. ${ }^{16}$

Degradation using photochemical reactor was carried out using $2.5 \mathrm{~kg}$ of $20 \%$ acetonitrile residue and $2.5 \mathrm{~kg}$ of deionized water. In the essay using hydrogen peroxide, besides these amounts of water and residue, $500 \mathrm{~mL}$ of $50 \%$ hydrogen peroxide solution were added.

In evaluating photolysis under irradiation of a lamp, $500 \mathrm{~mL}$ of $20 \%$ acetonitrile residue and $500 \mathrm{~mL}$ of deionized water were used.

\section{Results and Discussion}

Initially the content of dissolved organic carbon (DOC) in the original residue was determined in triplicate and a value of $205 \pm 6 \mathrm{~g} \mathrm{~L}^{-1}$ was obtained. This value is very similar to the theoretical one $\left(214 \mathrm{~g} \mathrm{~L}^{-1}\right)$, calculated for a mixture containing acetonitrile and water in a 40:60 rate. The initial $\mathrm{pH}$ value of the residue was 6.0.

As acetonitrile and water form an azeotropic mixture containing $84 \%$ (volume) in acetonitrile with a low boiling point $\left(76^{\circ} \mathrm{C}\right),{ }^{17}$ some essays were carried out in order to verify the proportion of acetonitrile lost by evaporation. The first experiment measured the reduction of DOC in the residue and simultaneously the increasing of DOC values in the collecting vessel containing water, during exposition to sunlight for $2 \mathrm{~h}$. DOC value in water was altered from 1.0 to $2.2 \mathrm{~g} \mathrm{~L}^{-1}$ while the residue DOC decreased from 93300 to $82300 \mathrm{~g} \mathrm{~L}^{-1}$. These values indicate that besides the evaporation, other decomposition processes must be occurring, since the increase in the water DOC is not proportional to the decrease in the residue DOC.

Aiming to confirm these results, another experiment was carried out to compare the reduction of acetonitrile, measured through DOC, during (a) sunlight exposition, (b) control experiment in darkness and (c) heating in an oven at $35-45^{\circ} \mathrm{C}$. These results are shown in Figure 1.

Figure 1 shows that in the darkness control experiment and in the experiment simulating heating observed during sunlight exposition, the reduction of acetonitrile,

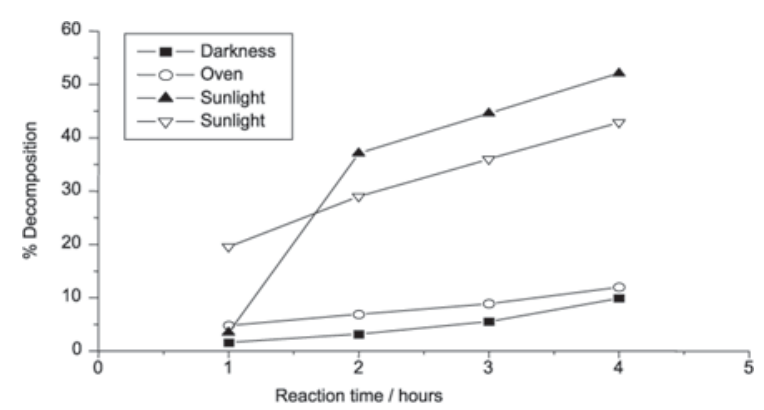

Figure 1. Comparison among acetonitrile decomposition/evaporation in (匹) darkness control experiment, $(O)$ an oven $\left(35-45^{\circ} \mathrm{C}\right)$ and $(\boldsymbol{\Lambda}, \nabla)$ during sunlight exposition for 4 hour.

determined through DOC, was inferior to $12 \%$ in $4 \mathrm{~h}$. Nevertheless, in the experiment with sunlight exposition (photolysis), the reduction of acetonitrile content varied between 43 and $52 \%$ after $4 \mathrm{~h}$. Zhuan et al. ${ }^{14}$ also observed that the oxidation of acetonitrile at $32{ }^{\circ} \mathrm{C}$ was not a thermal process once it did not happen in the absence of a radiation source. Therefore, it can be said that during the photolysis, some evaporation occurs but this is not the main factor causing DOC reduction. It is worthwhile noticing that the rate of acetonitrile decomposition during photolysis varies with the light intensity. During the two experiments shown in Figure 1, the light intensity varied from 1.1 to $2.0 \mathrm{~mW} \mathrm{~cm}^{-1}$, at $365 \mathrm{~nm}$.

The results obtained during the experiments of solar photolysis, oxidation using hydrogen peroxide in the presence and absence of sunlight, degradation by Fenton and photo-Fenton processes are presented in Figure 2. All these experiments were run simultaneously to assure that they were exposed to the same sunlight intensity. According to Figure 2, the processes using a radiation source are $50 \%$ more efficient to decompose acetonitrile residues and Fenton was $4 \%$ more efficient than hydrogen peroxide and photolysis processes.

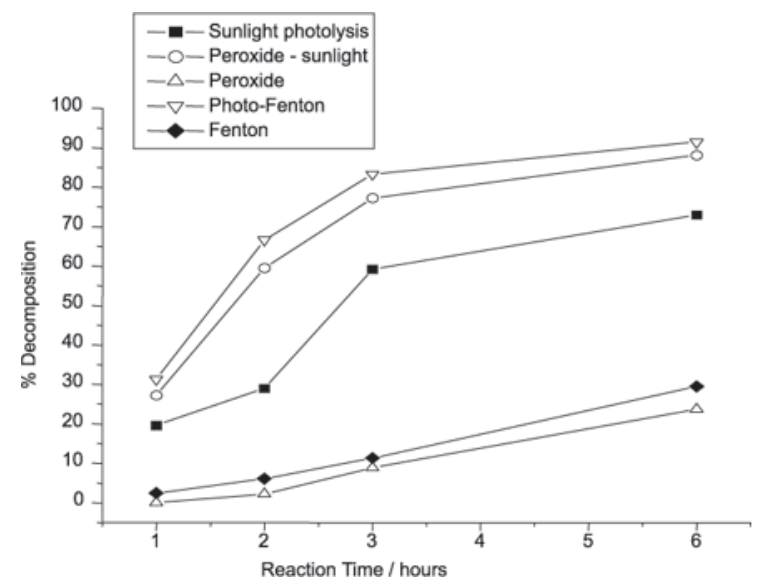

Figure 2. Comparison among sunlight photolysis (ם), oxidation using hydrogen peroxide in the presence $(O)$ and absence $(\triangle)$ of sunlight, degradation by Fenton $(\diamond)$ and photo-Fenton $(\nabla)$ processes for the degradation of aqueous acetonitrile residues. 
New experiments were done in which the processes under sunlight exposition were observed for a longer period of time. Furthermore, the ferrioxalate process of oxidation ${ }^{16}$ was also evaluated. The results of these experiments are shown in Figure 3. It can be seen that the processes kinetics are little distinct during the first hours of sunlight exposition. However, after 11 hours the percentage of decomposition varies in the range of $87.3\left(\mathrm{H}_{2} \mathrm{O}_{2}\right)$ and $94.1 \%$ (ferrioxalate), that is, no meaningful difference. Under exposition for 27 hours, DOC values decreased by more than $99 \%$ for all the sunlight processes studied.

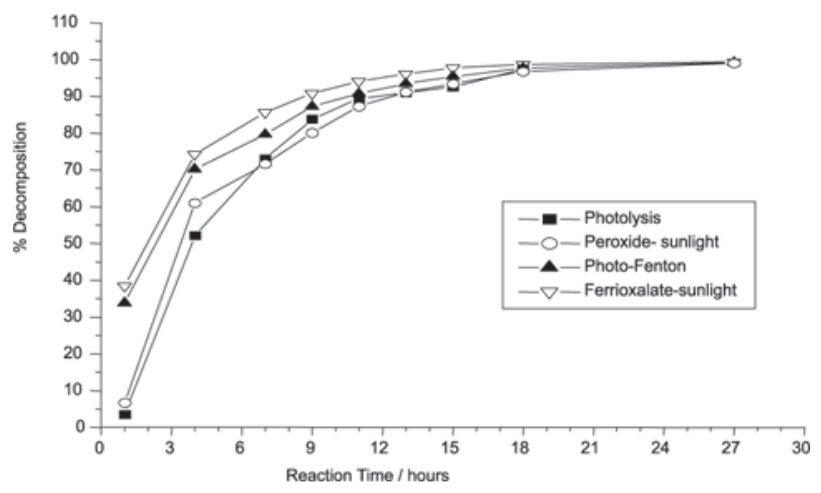

Figure 3. Comparison among photolysis (ם), oxidation using hydrogen peroxide under sunlight $(O)$, photo-Fenton under sunlight $(\boldsymbol{\Delta})$ and ferrioxalate under sunlight $(\nabla)$ processes for the degradation of aqueous acetonitrile residues.

RP-HPLC aqueous residues of acetonitrile and solutions of acetonitrile P.A. in deionized water were submitted to photolysis, oxidation using hydrogen peroxide and degradation by photo-Fenton under sunlight. These tests were performed to check if both solutions presented the same behavior. However, a very similar decomposition rates were observed for both systems. Therefore, it can be concluded that the presence of a small quantity of agrochemical products analyzed by RP-HPLC did not interfere in the degradation of acetonitrile. It was also observed that the method produced reproducible degradation of aqueous acetonitrile residues, but the rate of decomposition varies with light intensity; and that slight differences among the processes tend to disappear with increasing sunlight exposition time.

The next step was to realize the degradation process in a photochemical reactor using artificial light, with no oxidizing reagents. Nevertheless, after 1.5 hours under UV light, no meaningful reduction of DOC values was observed. Addition of hydrogen peroxide (rate 1:1) to the mixture used in the photochemical reactor promoted total degradation after 40 hours.

To achieve a cheaper degradation procedure that could be more widely used, the system using a common light lamp (mercury vapor and tungsten filament), a Becker and a magnetic stirrer were used. The results obtained with this system are shown in Figure 3, with the others profiles for comparison. According to these results, the degradation of $1 \mathrm{~L}$ of an aqueous residue containing $20 \%$ of acetonitrile reached $99.9 \%$ in 30 hours. In this experiment, DOC was reduced from 87,300 to $18.4 \mathrm{mg} \mathrm{L}^{-1}$, showing that the process is efficient to degrade acetonitrile residues.

Further studies will be done to identify possible toxic intermediates and to check if it can be used without major environmental concerns.

\section{Conclusion}

According to the results obtained, aqueous acetonitrile residues containing up to $20 \%$ of acetonitrile can be easily decomposed using photolysis, hydrogen peroxide oxidation under sunlight, photo-Fenton and ferrioxalate processes. Although being cheaper and easily applied, the widespread use of the photolysis process still requires additional studies to verify if volatile toxic intermediates are formed during the decomposition.

\section{Acknowledgments}

The authors are grateful to Dr. Carol H. Collins for RPHPLC discussions and language assistance and to Cláudia P.A.B. Teixeira for the support during the development of AOP essays. The authors wish to express their appreciation for FAPESP financial support.

\section{References}

1. Amaral, S.T.; Machado, P.F.L.; Peralba, M.C.R.; Camara, M.R.; Santos, T.; Berzele, A.L.; Falcão, H.L.; Martinelli, M.; Gonçalves, R.S.; Oliveira, E.R.; Brazil, J.L.; Araújo, M.A.; Borges, A.C.A.; Quim. Nova 2001, 24, 419.

2. Cunha, C.; Quim Nova 2001, 24, 424.

3. Pacheco, E.B.; Hemais, C.A.; Quim Indust. 2000, 716, 26.

4. Micaroni, R.C.C.M.; Bueno, M.I.M.S.; Pereira-Filho, E.R.; Arruda, M.A.Z.; Jardim, W.F.; Abstr. of Papers of the Am. Chem. Soc. 2001, 221, 108-CHED.

5. Memorandum of the Plenary Meeting of $19^{\text {th }}$ CSTEE (Scientific Committee for Toxicity, Ecotoxicity and the Environment), Brussels, Belgium, 2000, in http://europa.eu.int/comm/food/ whatsnew/oldnews0101_en.html, accessed in September, $18^{\text {th }}$, 2003.

6. Ichinoki, S.; Yamazaki, M.; Ogawa, E.; Kashihara, M.; Ishizaki, J.; Bunseki Kagaku 1998, 47, 591.

7. Ribeiro, L.V.R.; Grespan, C.B.; Collins, C.H.; Collins, K.E.; Bruns, R.E.; J. High Resol. Chromatogr. 1999, 22, 52. 
8. Gilomen, K.; Stauffer, H.P.; Meyer, V.R.; Chromatographia 1995, 41, 488

9. ISI Web of Science, http://isi3.newisiknowledge.com/ portal.cgi, using the keywords "HPLC and acetonitrile" in the year of 2003, accessed in September, $18^{\text {th }}, 2003$.

10. Sheth, R. O.; https://www.denix.osd.mil/denix/Public/Library/ PRO97/709hplc.html, accessed in September, 18 ${ }^{\text {th }}, 2003$.

11. Spectrum ${ }^{\circledR}$ Chromatography, http://www.lplc.com/sale/s3.htm, accessed in September $18^{\text {th }}, 2003$.

12. Nieder, M.; Sunarko, B.; Meyer, O.; Appl. Environ. Microbiol. 1990, 56, 3023.

13. Lichtin, N.N.; Avudaithai, M.; Environ. Sci. Technol. 1996, 30, 2014.
14. Zhuang, J.; Rusu, C.N.; Yates Jr., J.T.; J. Phys. Chem. B 1999 , 103, 6957.

15. Emilio, C.A.; Jardim W.F.; Litter, M.I.; Mansilla, H.D.; $J$. Photochem. Photobiol. A 2002, 151, 121.

16. Nogueira, R.F.P.; Alberici, R.M.; Mendes, M.A.; Jardim, W.F.; Eberlin, M.N.; Ind. Eng. Chem. Res. 1999, 38, 1754.

17. The Merck Index, Merck \& Co. Inc.: Rahway, New York, $12^{\text {th }}$ ed., 1996.

Received: September 16, 2002

Published on the web: June 29, 2004

FAPESP helped in meeting the publication costs of this article. 